\title{
Virtual and Augmented Reality in the Art of Lucio Fontana
}

\author{
Agata Marta Soccini \\ Univ. of Torino, Computer Science Dept. \\ Corso Svizzera 185, Torino, Italy \\ soccini@di.unito.it
}

\begin{abstract}
Virtual Reality and Augmented Reality are cutting edge technologies that can be used for several purposes, from entertainment to telemedicine. The attention given by experts and researchers from several different disciplines led us to investigate on the roots of these novel tools. We claim that, beside the technologic heritage, paradigms of mixed reality are also the result of the social needs and human curiosities that were expressed through art in history. The AVAR Project (Art in Virtual and Augmented Reality) aims at finding the tracks of VR and AR concepts in history of Art, through the analysis of artworks and manifestos. In this paper we present the first studies, based on Lucio Fontana. We spot the links between Spatialism and the concepts of immersion, 3D visualisation, user experience, and real and artificial worlds. We conclude reporting the results, and the pertinent considerations on the need to be open to a multidisciplinary approach in building culture. Further investigation on the links among VR, AR, history of art, and contemporary art, can bring tech community a solid knowledge base on how to experiment novel virtual experience paradigms.
\end{abstract}

Virtual reality. Augmented reality. Lucio Fontana. Contemporary art. Immersion. 3D. User experience.

\section{INTRODUCTION}

Virtual Reality and Augmented Reality are considered as cutting edge technologies and are respected in the Tech world. In the history of technological evolution they represent the ultimate implementation of multimedia algorithms together with artificial intelligent agents and real time render systems. This complicated mix of efforts would be a waste if used just for games, and that is why it attracts many professionals and researchers from several different disciplines.

While many recognise the potentiality and the multi-disciplinary power of this technological masterpiece, the success of VR and $A R$ is rarely seen as the latest novel tool that science is offering to art. In this paper we claim that paradigms of mixed reality were born not only thanks to the result of the technologic evolution, but also, and mostly, thanks to the social needs and human curiosities that were expressed through art in history. The concepts intrinsic in the capability to create parallel worlds using novel technologies based on scientific discoveries can be seen as the natural evolution of artistic ambitions of humanity.
In section 2, we present AVAR, a multi-disciplinary international project that aims at finding roots of technologic novelties, in particular of Virtual and Augmented Reality, in the history of art, in particular in Contemporary Art.

In section 3, as a first study, we purpose an analysis of the poetic of Lucio Fontana, father of the Spatialism. In his manifestos, Fontana underlines several aspects of art that can be considered as the basis of the concepts of representation of virtual environments.

In section 4, we report our conclusions and considerations, and invite readers to investigate links between VR, AR and history of art, as the tech community can take advantage of history of art lessons as tips to create novel paradigms.

\section{PROJECT OVERVIEW}

Mixed Reality is having a lot of attention in the market of customised entertainment today. In Figure 1, we see the cover of the Time magazine claiming that Virtual Reality is a source of surprising joy, and is about to change the world. After an early trial period in the $70 \mathrm{~s}$, and a big success in the 90s, Virtual and Augmented Reality 
had no big news for more than a decade. This was related to all approaches to the subject: research did not implement new paradigms or innovative algorithms and systems; the market went slow; users' interest was lost in promises.

We had to wait for the new millennium trends in games and entertainment to see a new rise of this ensemble of technologies and their propagation.

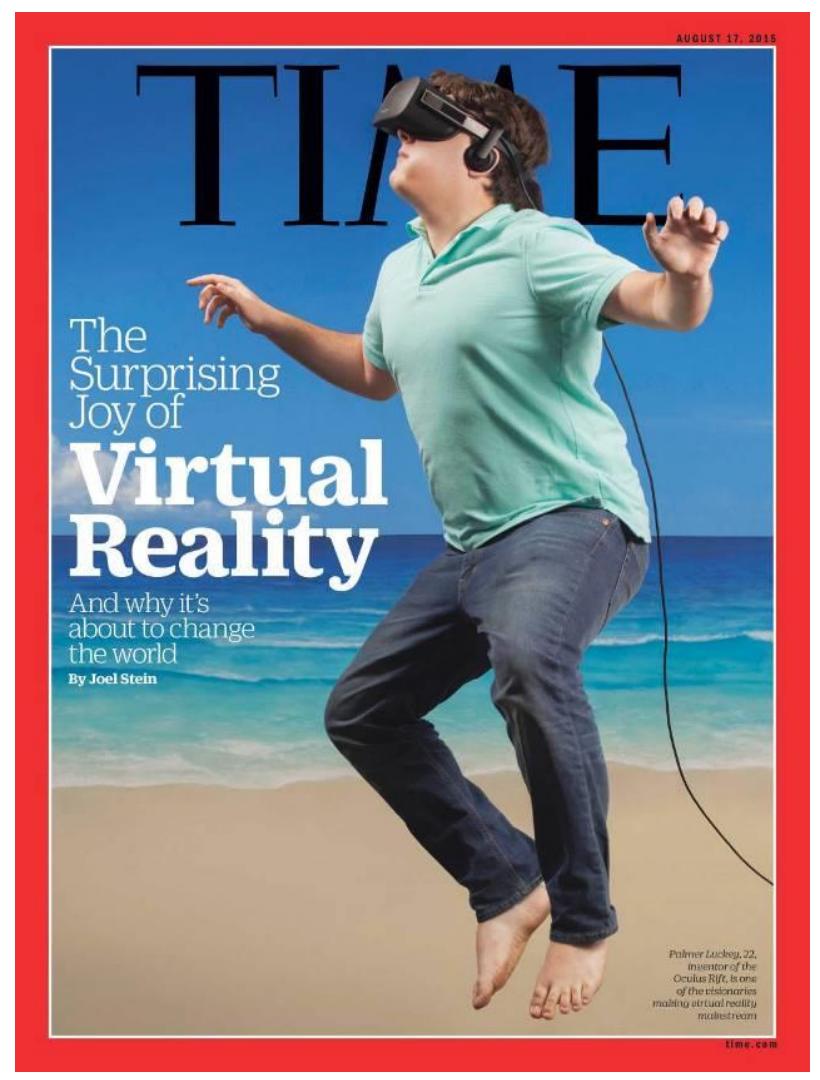

Figure 1: The cover of Time magazine. August 17, 2015

The link between the market of mixed reality and entertainment, and the link between entertainment industry and visual arts and artists, led us to investigate a transitive property of the involvement of principles and history of art in Virtual and Augmented Reality.

In history of art, VR and AR are barely considered. Some sporadic artists have done independent projects, and some attention was given by visionary museums, influenced by the market, but movements haven't appeared yet.

\subsection{Virtual Reality}

Let's focus on Virtual Reality first. The use of Virtual Reality (VR) for scientific purposes is well known and diffused; we can mention simulations of outer space environments and vehicles for prelaunch phases of space exploration missions (Soccini 2015); we can mention telemedicine and above all rehabilitation systems realised using
Virtual Reality existing devices. The use of Virtual Reality in art is way less famous and supported then the one in science, unless we want to consider those sides of entertainment that explore art.

While the potentialities and value of this novel set of paradigms, philosophies and devices for the realisation of artworks is recognised by major institutions, we underline the need to recognise the introduction of these new technologies as an evolution of media in history of art. Not only we are assisting to the rise of new paradigms and habits tied to new technologies, but also we are admiring the natural evolution of the existing techniques for creating artworks in the digital era.

The advent of Virtual Reality can be seen as the introduction of a new media to support the expression of evolving concepts tied to individuals, psychology, philosophy, society, politics, science, and all current times topics (Rheingold 1991). And that is what contemporary art is about. We can think of the introduction of digital technologies as the introduction of a new set of brushes and sculpting kits in the world of the available tools.

\subsection{Augmented Reality}

Augmented Reality (AR) is something technically very close to VR, but quite far in terms of use. A pure computer scientist would probably define augmented reality as a mix of digital and real mainly visual (but also acoustic and tactile) information that shares the basic technologies and the basic concepts with virtual reality and the gaming world. Of course they would be right, and the difference in terms of algorithms is basically about making a device recognise what we see in the real world in a quite intelligent way, in order to put information together with the digital part (Azuma et al. 2001).

Design and use wise, augmented reality takes a strong distance from VR, as it is meant to be the base of a set of applications that support humans in their everyday activities. Augmented Reality offers not a simulation of specifically required experiences and environments, but a set of tools that enhances, and often eases, real experiences.

While analysing aspects of Augmented Reality, we focus on the power to increase the enjoyment of everyday experiences, to grasp people's attention and lead it to specific paths and details, to underline and give a meaning to chosen elements. These are the main aspects we believe are a heritage of the culture of contemporary art. 


\subsection{History of Art, Contemporary Art, Digital Art}

The history of Art is the path along time of the evolution of the features of what we call art. So what do we call art?

We do not have the ambition to define what is and what is not art in this paper -supposing it was possible-, but we focus on searching some common features in major artists' works and manifestos that are somehow still alive in VR and AR.

Literally speaking, contemporary art should refer to art made by living artists, or art created during our lifetimes. According to this definition, all art has been contemporary (Nannucci).

When we talk about contemporary art, however, we do not refer to the art of living artists in general, but to the art produced between the birth of the twentieth-century avant-gardes and today's expressions of new media digital art.

As historically artists lean on technologic evolution to experiment new media in their productions, one of the latest trends in contemporary art is the use of digital technologies in the creative process (Grau 2002).

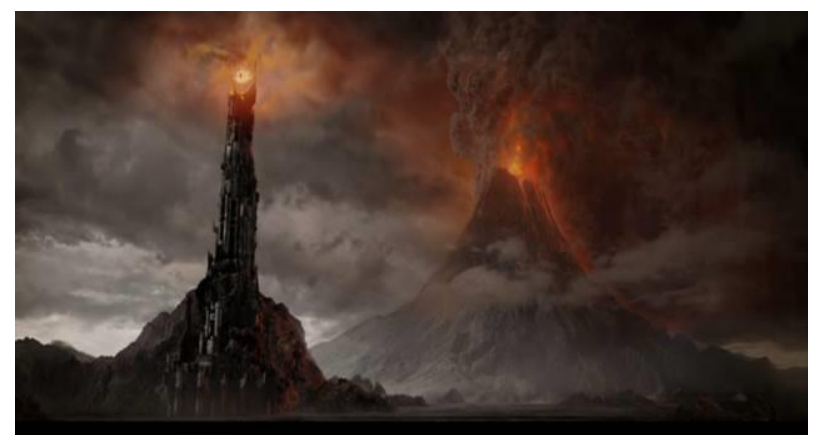

Figure 2: A digital landscape from the movie "Lord of the Rings"

Digital technologies used for digital arts vary from electric lights to complex electronic components, from easy media generating applications to 3D modelling software. In Figure 2 we can see a computer-generated image, realised using fluid simulation software, digital sculpting tools, and rendering algorithms.

\subsection{Art in Virtual and Augmented Reality: the AVAR project}

This paper presents the first studies of a combined research on contemporary Virtual and Augmented Reality user experience design patterns, and the analysis of a an evolution of philosophy and techniques of history of art.

At the Computer Science Department of University of Torino, we created a network of researchers and experts whose background vary from computer science to interaction design, from history of art to architecture. While the hub is in Torino, the team is spread around the world, including curators in Canberra, Australia, digital artists in Los Angeles, California, and a team of architects in Milano, Italy. Our team common interests are visual arts, technologies, contemporary arts, but, above all, the connections among them and the confidence in the potentially astonishing results of a multi-disciplinary approach to all these disciplines.

The project Art of Virtual and Augmented Reality (AVAR) is at its very beginning and aims at building a solid multidisciplinary knowledge on VR focused on one side on the artistic potentiality of virtual reality technologies and devices, and on the other side on the research of the roots of VR technologies in the history of art.

We basically started planning a chronological analysis of the main artistic movements in history, starting from now and going backwards. For every step, we will perform this analysis.

- Define the dates of the artistic eras

- In every era, spot the movements and the main features of every movement

- For every movement, we seek whether or not the movement and his representatives have done any studies or any attempts to approach those subjects that are intrinsic in the goals of mixed reality

- In case we find a link, we go deep searching what kind of concept can be considered as early studies of representation of reality that are, maybe unconsciously, used in the development of mixed reality applications.

- We define design and interaction paradigms, and enrich the knowledge base of the historical novelties that brought to the current computer graphics trends.

The first step we took into history of art starts from the present and goes back to the first moment when Contemporary art, as we define it now, appears.

Among all currents and artists, as the title of the paper says, we honour the master Lucio Fontana. Starting from the 'White Manifest', and the consequent 'Technical Manifest of the Spatialism' was an immediate choice. 


\section{LUCIO FONTANA AND THE VIRTUAL AND AUGMENTED REALITY}

Lucio Fontana is best known for his concept of space that goes over the canvas, and, in the production of his experimental art, he is one of the first artists that explores the sense of immersion.

We just described the basic concepts of the Art of Lucio Fontana using a few keywords that are also the technical terms commonly used to define Mixed Reality.

The cuts on the canvases take users not only in a new space but also guide us through a surprising new experience. As we can see in Figure 3, his 'Spatial Concepts' challenge the limits of a known technique, in this case painting, and take it closer to science, technology and art (Chiantore et al 2013). The canvas acquires new meanings and becomes three-dimensional.

The artist is telling us that every physical object is not only what we expect to see, but can also provide further information. It gives us the idea to enrich the importance of everyday experience with novel links and concepts.

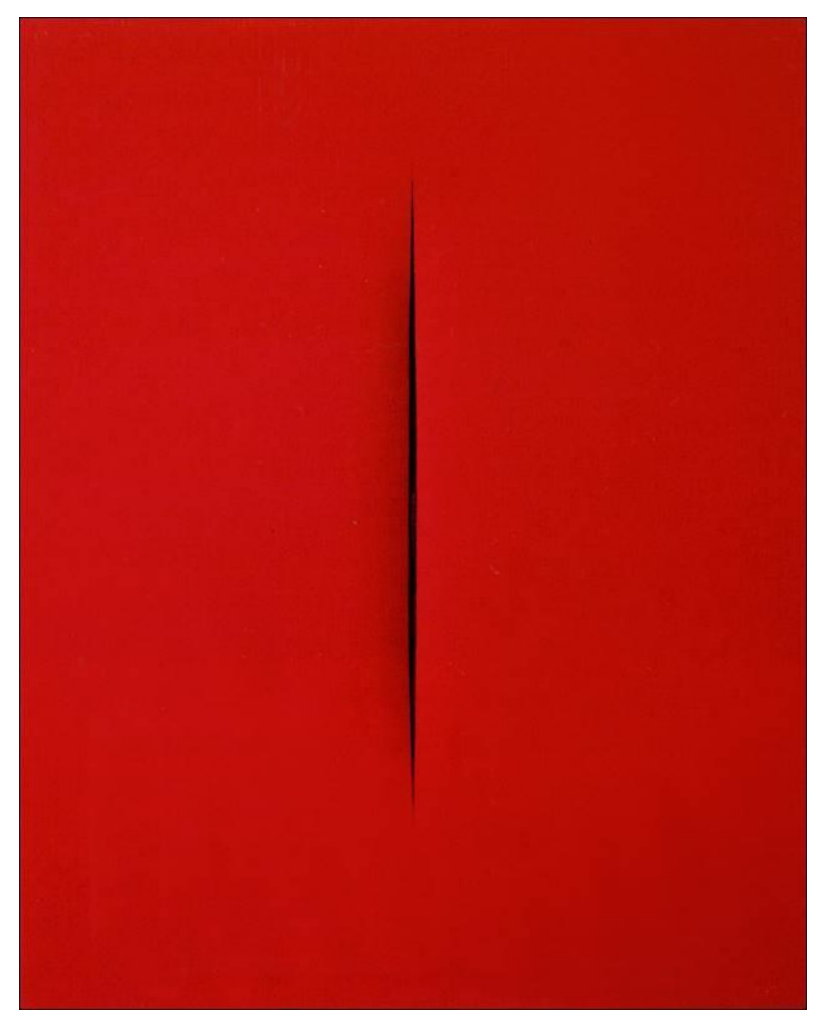

Figure 3: Concetto Spaziale, L'Attesa (Spatial Concept, Waiting). 1965. Private Collection

Behind every Canvas with a cut, the artist wrote some words. Those few words are often notes on his actual situation or his everyday life, more than conceptualisations of life, art, and philosophy, as we might expect from such an intellectual. The experience we live, as curious viewers, is that, after catching our attention on something unusual, the artist takes us through a new world, and then he wants us to go back to reality. In this case it's his reality he wants to share with us. The artist becomes the designer and the developer of a game we are invited to play, and, as every serious game, the experience takes us into deep psychological and philosophical considerations.

The "Tagli" (literally, cuts) is the most famous and one of the latest series from Fontana, and therefore represents a mature philosophy of his artistic expression, but the author previously introduced other reality-questioning artworks (Gottschaller 2012). The most direct and immediate way to convey the will to transport the viewers can be found in the installations, where the artist leads observers through guided multimedia experiences. This aspect will be further discussed in the Immersion section, but in the meanwhile we can see in Figure 4 an example of a three-dimensional digital installation.

In these cases, and in others, we can spot some user experience basis. In the art of Lucio Fontana, observers become beneficiaries and actual users. The creation of the sense of immersion, together with the change of the role of a user, and the early rough design of a user experience, can be therefore considered as an ante-litteram definition of mixed reality.

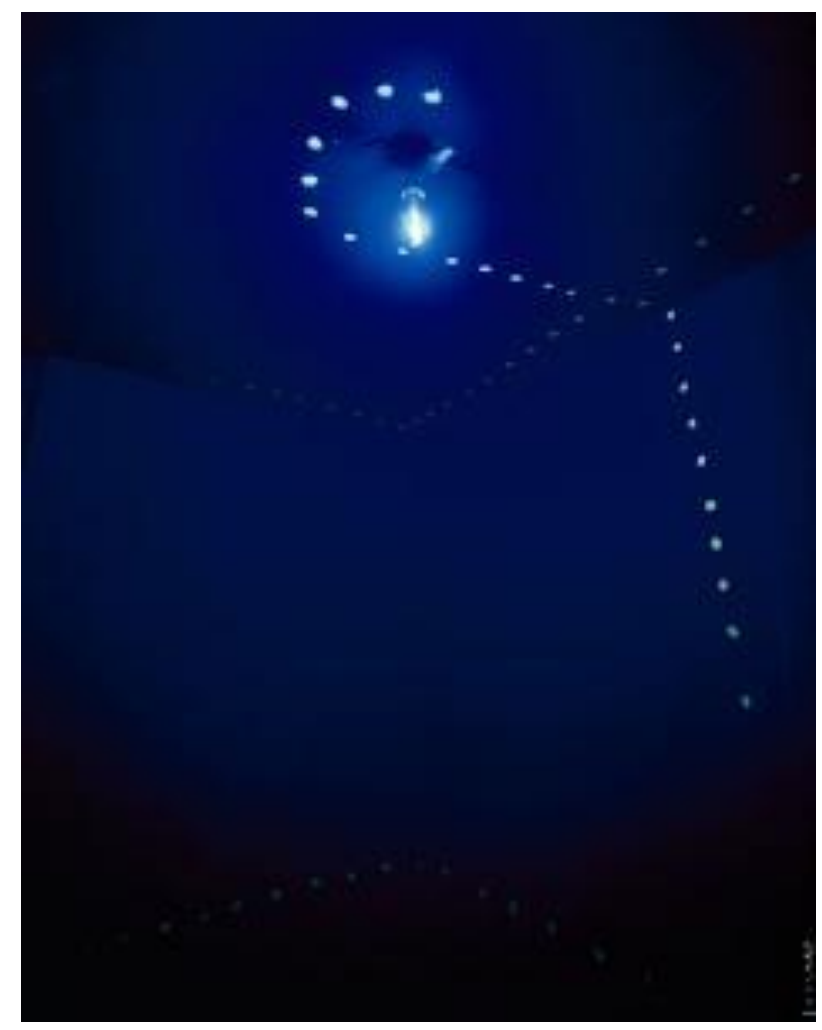

Figure 4: Ambiente Spaziale (Spatial Ambient). 1967. Musée d'Art Contemporain, Lyon, France 
To support our investigation, we mention Fontana's introduction to the "White Manifest". Scientific discoveries have a deep impact on the organisation of everyday life. The dominance of matter and space imposes people some life conditions that were never reached before. The psychic structure of humans dramatically changes (Fontana 1946). And therefore the need of expression and the production of art.

Fontana creates, among other artworks, the ceilings of two pavilions at the 31st Milano Fair. He is inspired by science in the creation of extra terrestrial sensorial-questioning artificial environments.

Among all digital graphics technologies, Virtual and Augmented Reality potentially provide the most powerful and involving experiences, as they tend to transport users in parallel worlds. The main features that characterise VR and AR are the treedimensional and stereoscopic representation, and the sense of immersion - with different meanings in $\mathrm{AR}$ and VR.

Following this brief analysis, we searched for tracks and definitions of four main outlines we implicitly just mentioned.

- Third dimension

- Sense of immersion

- User experience

\subsection{The third dimension}

The representation of the third dimension has always been a challenging goal for artists, both in the representation of reality or in the creation of imaginary worlds. The canvas, like a screen, is a two dimensional world that can be decorated and tortured in order to cheat human perception and give the impression of a third dimensionality, that in reality does not exist.

In the cuts, light passes through the cut area and creates a chiaroscuro. Limits between painting, sculpture and decoration are overcome. The canvas is no more the $2 \mathrm{D}$ space in which our world has to fit; it is just a part of the whole reality it is mixed with. Let's think of AR. We have a similar experience when we download basic mobile applications on our smartphones. In a few minutes we look at the screen and see through the camera our real living room, but full of dinosaurs. The screen is not just a representation of a $2 \mathrm{D}$ image, but it becomes a window to a half real half fake 3D world.

In his manifestos, Fontana (1951) says that in this mechanical era, a painted canvas and a standing chalk have no more reason to exist. He underlines the need to go over paintings, sculpture, poetry and music, supporting novel representations of the space, based on media given by technologic advancement.

We can take this as a premonitory push to the development of digital 3D art.

\subsection{Immersion}

Fontana talks about setting art free from matter. In his installations, he creates artificial environments before the digital era.

His first "Ambient Installation" in Milano, at "Galleria del Naviglio", is the first artwork ever that used electrical light: in a dark room, a black light gives objects a violet aura, and the viewer is confused on the perception of the space. The artist is taking the user into a different world, where time, space, movement, perception, are totally isolated from the real world and driven by the artwork (Ryan 2001). The feel the same sense of immersion when we wear VR visors. We suddenly abandon the real world and jump into an audio-video threedimensional experience that could be realistic or imaginary, but in both cases is completely detached from the real world.

Perception is questioned through the creation of rooms with the shape of a labyrinth with fluorescent decorations, as much as it is tricked when we run away of dinosaurs in an artificial world given by a headset.

\subsection{The USER and the EXPERIENCE}

According to Fontana, time and space, and movement through time and space, are the basic elements of the new art. We are very far from any reference to paintings, sculpture, or any other product seen so far in history of art.

Instead of creating evocative objects, Fontana seems to focus on the observers and on what they are going to live when they meet the artwork. The concept of observer is therefore intrinsically obsolete; we can start talking about users.

Starting with Spatial Movement, experimental knowledge takes the place of imaginative knowledge. Users are involved in a practical and sensorial, not only evocative and interpretative, way (DigitalArtArchive). The intention of Fontana is to put together all human experiences in one synthesis, which ultimately consists in an expression of being (Fontana 1947).

\section{SUMMARY AND CONCLUSIONS}

In this paper we put the basis for the investigation on the connections between evolution of art 
techniques and evolution of technology of the images.

To delineate our project, we started from the background. We introduced the concept of Virtual Reality (VR) and Augmented Reality (AR) in terms of products of the technological advancements as well as in terms of new media supporting art production. We also outlined the role of Virtual and Digital art in Contemporary art and in history of art in general. Starting from there, we introduced AVAR Project. AVAR was born from a set of common interests shared by researchers and professionals spread worldwide, and aims at combining knowledge of computer science and design with the heritage of history of art.

The first studies of the AVAR Project are a parallel between the most relevant features of VR and AR and their relevance in the art of Lucio Fontana. 1.The three-dimension representation, 2.the sense of immersion, and 3.the user experience concept, are the most evident connections between current AR and VR concepts and design trends, and the basics of contemporary art, seen through the eyes of the master.

By underlying the presence in history of art of tracks of the main concepts used in the design of mixed reality applications, we demonstrated the following points:

- Virtual and Augmented Reality paradigms have roots in contemporary art concepts.

- VR and AR can be considered as new media capable of giving expression of artists' creativity.

- Once again in history, technology and science are sharing their knowledge with artists to provide them with stronger and novel media to express creativity.

- VR and AR technologies and devices are the social and commercial evolution not only of tech trends, but also of artistic trends.

This questions the role and the credit of technology, which of course is crucial for innovation and scientific evolution, but is not isolated. Technologists should admit - or realise - that, beside the sense of intrinsic omnipotence it carries, technology alone is a pure exercise.

We support further investigation on the links between Virtual and Augmented Reality and major artists, especially contemporary artists, as we believe that such studies will give the tech community novel ideas on how to innovate mixed reality paradigms.

\section{REFERENCES}

Azuma, R., Baillot, Y., Behringer, R., Feiner, S., Julier, S., and Maclntyre, B. (2001) Recent advances in augmented reality. Computer Graphics and Applications, IEEE, 21(6), pp. 34-47.

Chiantore O., Ploeger R., Poli T., Ferriani B. (2013) Materials and techniques in the pictorial oeuvre of Lucio Fontana. Studies in Conservation, 57(2), pp. 92-105.

DigitalArtArchive

https://www.digitalartarchive.at/database/databaseinfo/archive.html (retrieved 15 March 2015).

Fontana, L. (1946) White Manifesto.

Fontana, L. (1947) First Manifesto of the Spatialism.

Fontana, L. (1951) Technical Manifesto of the Spatialism.

Gottschaller, P. (2012) Lucio Fontana, The Artist's Materials. Getty Publications, Los Angeles, California, USA.

Grau, O. (2002) Virtual Art. From Illusion to Immersion. MIT Press, Cambridge, Massachusetts, USA.

Nannucci http://www.mfa.org/collections/object/allart-has-been-contemporary-549280 (retrieved 15 March 2015).

Rheingold, H. (1991) Virtual Reality: Exploring the Brave New Technologies. Simon \& Shuster Adult Publishing Group.

Ryan, M. L. (2001) Narrative as virtual reality: Immersion and interactivity in literature and electronic media. Johns Hopkins University Press.

Soccini, A. M. (2015) Virtual Reality for Collaborative System Engineering supporting ESA experimental vehicles. EuroVR 2015, Lecco, Italy, 15-16 October 2015, Eurographics, London, UK. 